\title{
From the diagnosis to the therapeutic management: cerebral fat embolism, a clinical challenge
}

This article was published in the following Dove Medical Press journal: International Journal of General Medicine

\author{
Maenia Scarpino' \\ Giovanni Lanzo' \\ Francesco Lolli \\ Antonello Grippo 3 \\ 'Unit of Neurophysiopathology, \\ Neuromuscolar Department, AOU \\ Careggi, Florence, Italy; ${ }^{2}$ Neuroscience \\ Department (NEUROFARBA), \\ University of Florence, Florence, Italy; \\ ${ }^{3}$ Intensive Rehabilitation Unit, IRCCS \\ Fondazione Don Carlo Gnocchi, \\ Florence, Italy
}

\begin{abstract}
Cerebral fat embolism (CFE) is an uncommon incomplete type of fat embolism syndrome (FES), characterized by purely cerebral involvement. It usually occurs 12-72 hours after the initial trigger, mainly represented by closed, long-bone multiple fractures of the lower extremities. Neurological manifestations are mainly characterized by headache, confusion, seizures, focal deficit, and alteration of the consciousness state up to coma onset. It represents a diagnostic challenge, above all when secondary to uncommon nontraumatic causes, because neurological signs and symptoms are variable and nonspecific, not satisfying the Gurd and Wilson's criteria, the diagnostic features most widely used today for FES diagnosis. Neuroimaging (mainly MRI, but in some cases, brain computed tomography too) can hasten the diagnosis, avoiding other unnecessary investigations and treatment. Usually self-limiting, CFE may sometimes be fatal. Treatment is to date mainly supportive and prophylactic strategies are considered an important tool to decrease the development of fat embolism and, consequently, the rate of CFE. Keywords: cerebral fat embolism, neurological deterioration, neuroimaging, prophylactic strategies
\end{abstract}

\section{Introduction}

Cerebral fat embolism (CFE) is an incomplete type of fat embolism syndrome (FES), a rare clinical condition caused by embolization of fat particles into multiple organs, characterized by purely cerebral involvement. ${ }^{1-5} \mathrm{CFE}$ has an incidence of $0.9 \%-2.2 \%$ and is more frequent after closed, long-bone fractures of the lower extremities, particularly with multiple ( $\geq 3$ sites) fractures ${ }^{6,7}$ Although it is usually self-limiting, it may be fatal (mortality rate of up to $10 \%){ }^{8}$ Correct and early recognition of CFE remains an important goal in the diagnostic management of patients who show a sudden onset of neurological signs and symptoms.

In fact, the presence of isolated neurological symptoms and signs, in the absence of simultaneous pulmonary and/or dermatological manifestations, represents a diagnostic challenge, not satisfying the Gurd and Wilson's criteria, the diagnostic features most widely used today for FES diagnosis. ${ }^{9}$ To date, no universal criteria for FES diagnosis have been defined and even in terms of Gurd and Wilson's criteria, no justifications for the number of features needed for the diagnosis have been provided. This is probably a consequence of the fact that only a small number of patients who undergo fat embolism (FE) develop later signs and symptoms due to a multisystem dysfunction, mainly involving lungs, brain, and skin. ${ }^{10}$ It is only in this latter scenario, in which the classical triad of cerebral, respiratory, and cutaneous manifestations is present $(1 \%-29 \%)$, that the term FES is applied and Gurd and Wilson's criteria are satisfied. ${ }^{11-14}$
Correspondence: Antonello Grippo SODc Neurofisiopatologia, Dipartimento Neuromuscolo-Scheletrico e degli Organi di Senso, AOU Careggi, Largo Brambilla 3, 50134 Florence, Italy

Tel +39055 7949410

Fax +390557949409

Email agrippo@unifi.it 
In other cases, patients are usually asymptomatic or develop an incomplete type of FE, such as CFE..$^{1,10}$

\section{CFE epidemiology, etiology, and risk factors}

Besides the rather high rate of FE, occurring after mainly long-bone fractures or orthopedic procedures (67\%-95\%), only a small percentage of patients develop signs and symptoms due to a multisystem dysfunction. ${ }^{11,15}$ The incidence of FES differs (1\%-29\%) according to the cause (more frequent after long-bone fractures or orthopedic procedures) and the diagnostic criteria used. ${ }^{11-13}$ Indeed, the incidence of FES increases if, besides clinical criteria, postmortem examination is used. ${ }^{14}$

FE usually occurs within 12-72 hours after traumatic long-bone injuries, such as fractures of the femur, pelvis, and tibia, and after orthopedic procedures, such as intramedullary nailing and knee and pelvic arthroplasty. ${ }^{10,13,16-18}$ Other forms of trauma such as short-bone (ie, ribs or tarsal bone) injuries and massive soft tissue injury, but also bone marrow biopsy, bone marrow transplant, liposuction, and cardiopulmonary resuscitation are rarely responsible for FE. ${ }^{13,19-21}$ According to the literature, nontraumatic conditions are uncommon causes of FE. Diabetes mellitus, sickle cell disease, rosuvastatin use, fatty liver, fat emulsion infusion, facial fat injection, acute pancreatitis, and surgical procedures, such as video-assisted thoracoscopic surgical procedure in general anesthesia and pleural irrigation for empyema treatment are the most frequent nontraumatic causes of FE reported by authors. ${ }^{13,22-30} \mathrm{To}$ date, no specific disease or surgical procedure is associated with the development of CFE rather than of FES. However, CFE has an incidence of $44 \%$ after long-bone fractures (ie, femur and tibia), 39\% after surgical procedures of femur fractures, and $15 \%$ after elective orthopedic surgical procedures. ${ }^{5}$

No specific risk factors are associated with CFE. In general, the main risk factor for $\mathrm{FE}$ is young age (mean age $=30$ years), due to the high prevalence of severe trauma in this age group. ${ }^{5}$ Neuromuscular diseases are another risk factor reported in the literature: affected patients are fracture-prone because of possible disuse osteoporosis. ${ }^{31}$ Multiple or close fractures and a delay in immobilization can have a similar effect. ${ }^{11,13,32,33}$ Prolonged and laborious surgical procedures are also a known risk factor. ${ }^{13,16}$ In contrast, a decreased incidence of FES-CFE is associated with early immobilization and fixation of fractures. ${ }^{15}$ Finally, concerning sex, data are conflicting: some authors suggest that there is no sex predilection for FES-CFE development, whereas others report male gender as a risk factor. ${ }^{34,35}$

\section{CFE pathophysiology}

Two different theories have been postulated for FE: mechanical and biochemical. ${ }^{24}$ The mechanical theory is based on the increased intramedullary pressure after trauma with marrow passing into injured venous sinusoids and fat droplets released into the venous system. ${ }^{36}$ Fat droplets could then occlude the flow in small vessels, such as the pulmonary capillaries and subsequently, through arteriovenous shunts (ie, patent foramen ovale, which has an incidence of $20 \%-25 \%$ in the population) or directly through the pulmonary capillary bed, travel through the systemic circulation and reach the brain. For fat droplets to reach the brain circulation through the pulmonary capillary bed, several conditions are necessary: fat emboli should be numerous (100 particles per $\mathrm{mm}^{2}$ according to autopsy studies) and small $(7-10 \mu \mathrm{m})$, because particles $>20 \mu \mathrm{m}$ are blocked by the pulmonary filter. ${ }^{5,16}$ At the brain level, fat droplets determine local ischemia and inflammation associated with the release of inflammatory mediators, vasoactive amines, and platelet aggregation, all of which are responsible for the neurological signs and symptoms. ${ }^{3,5,16}$

According to the biochemical theory, the stressed state caused by trauma, surgical procedures, or the other aforementioned nontraumatic diseases, lead to hormonal changes associated with the systemic release of free fatty acids into the blood, which, in turn, are responsible for a microvascular inflammatory response and the production of fat droplets. ${ }^{37,38}$ This theory could explain the rare nontraumatic causes of FES. In addition, this mechanism, often typical in the brain, could easily explain CFE development: in this scenario, fat emboli would not have to pass across the pulmonary capillary bed to reach the brain circulation. The real pathogenesis of CFE is, however, still hypothetical.

\section{CFE clinical features}

FES onset is usually $12-72$ hours after the initial trigger. ${ }^{5,11,22}$ It is characterized by signs and symptoms due to a multisystem dysfunction, mainly involving the lungs, brain, and skin, and by other nonspecific symptoms, such as fever, hematuria, thrombocytopenia, anemia, disseminated intravascular coagulation, right ventricular dysfunction, shock, and death. ${ }^{5,10,11,39}$

The lungs and brain are the most often involved sites and neurological signs and symptoms can be seen in 33\%-86\% of patients either simultaneously or after pulmonary manifestations. ${ }^{5,10,11,39,40}$ The latter include dyspnea, tachypnea, and hypoxemia, and even acute respiratory distress syndrome. ${ }^{41}$ Dermatological manifestations are characterized by rash 
(petechiae) onset in nondependent regions of the body, such as the head, neck, and anterior thorax. 5,11,22

Concerning neurological manifestations, the main signs and symptoms reported in the literature range from headache, confusion, aggressive behavior, seizures, cortical blindness, dementia, apathy, focal deficit (such as hemiplegia, aphasia, agnosia) and alteration of the consciousness state with hallucinations (auditory or sexual hallucinations) up to coma onset. ${ }^{4,19,42,43}$ Other neurological signs and symptoms rarely reported in the literature are dystonia, decorticate posturing, and severe cerebral edema associated with refractory intracranial hypertension and hydrocephalus. ${ }^{5,11,3944}$ Neurological manifestations can also be characterized by paroxysmal sympathetic hyperactivity manifesting in arterial hypertension, sudden episodic tachycardia, sweating, tachypnea, and hyperthermia. ${ }^{45}$ This clinical feature is associated with an increase in blood catecholamine level due to the specific location of fat droplets in areas that can facilitate their release. ${ }^{45}$ Finally, some nonspecific symptoms, such as oliguria/anuria and jaundice have also been associated with CFE. ${ }^{11,22,39}$

Thus, it is clear that when neurological manifestations arise in isolation, such as in CFE, their variable and nonspecific nature means that they may be mistaken for other diseases, such as an acute stroke or, when characterized mainly by behavioral disorders, can be interpreted as a psychiatric disease, making CFE diagnosis challenging.

\section{CFE diagnosis}

In 1873, von Bergmann clinically diagnosed FES for the first time. ${ }^{46}$

FES diagnosis is only based on clinical features and on the exclusion of other diseases but it remains a difficult task as there are no universal criteria for diagnosis and laboratory tests are nonspecific. ${ }^{10}$ The lack of universal criteria is probably due mainly to the presence of incomplete types of FES that do not satisfy all the diagnostic criteria proposed until now. In addition, as in the case of CFE, the signs and symptoms are variable and nonspecific and so can be mistaken for other diseases. Gurd and Wilson's criteria are the diagnostic criteria widely used today but they are nonspecific and have never been validated in large cohorts., ${ }^{9,16,22}$

The modified Gurd's criteria too, although appearing more useful in CFE detection because of the inclusion of neuroimaging to define neurological involvement more accurately, have not yet been validated. ${ }^{16}$

Table 1 shows all the diagnostic criteria, including neurological evaluation that have been proposed until now.

Gurd and Wilson's criteria require at least two major criteria or one major criterion plus four minor criteria for a diagnosis to be made. ${ }^{9}$

Schonfeld et al instead proposed a quantitative measure based on clinical findings, according to which a score of more than five is necessary to make the diagnosis of FES. ${ }^{47}$

Table I Original Gurd and Wilson's criteria, ${ }^{9}$ Modified Gurd's criteria, ${ }^{16}$ and Schonfeld's criteria ${ }^{47}$ for diagnosis of FES

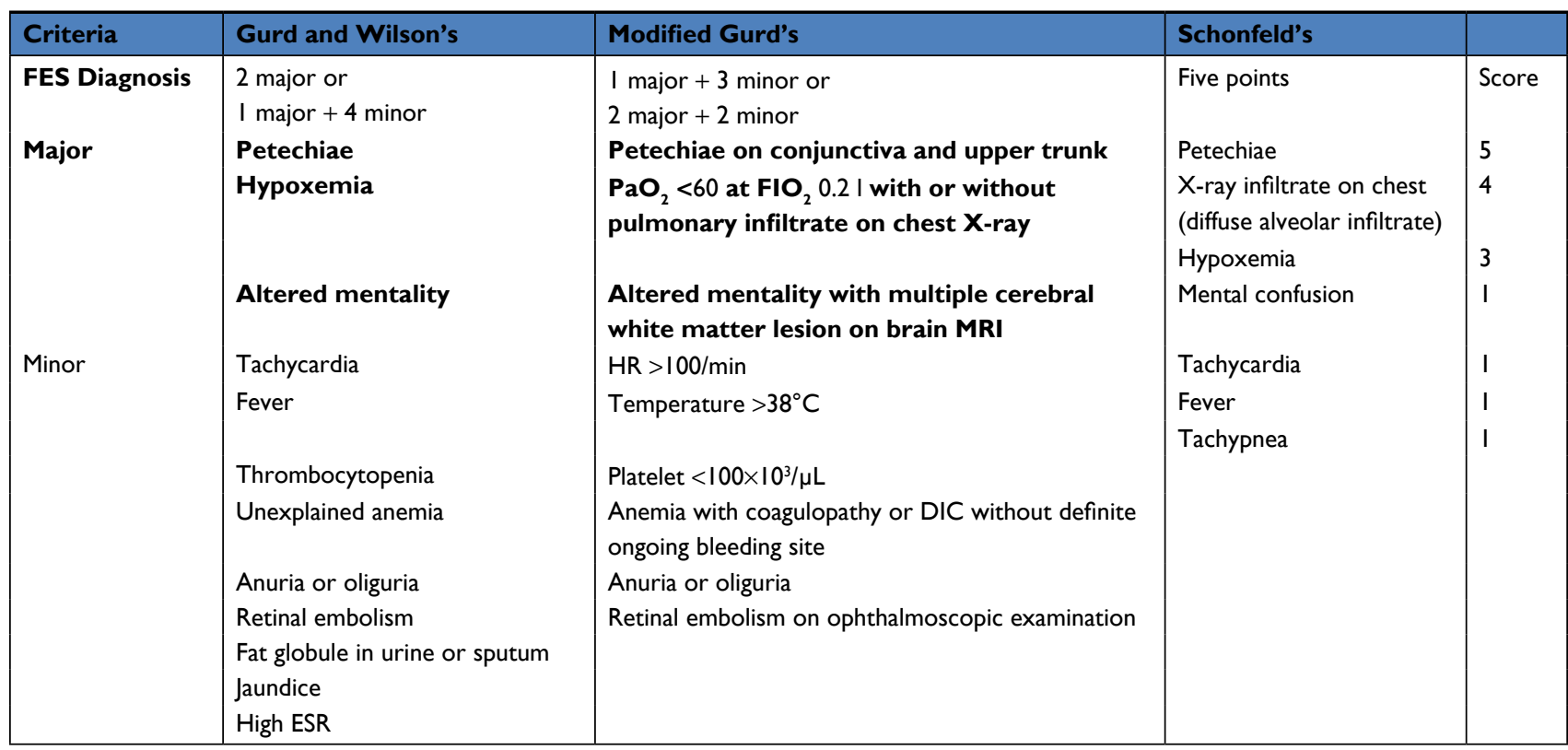

Note: Bold text represents major criteria.

Abbreviations: DIC, disseminated intravascular coagulation; ESR, erythrocyte sedimentation rate; FES, fat embolism syndrome; HR, heart rate; PaO2, arterial oxygen pressure. 
As we will see later, the modified Gurd's criteria need the presence of the association between clinical criteria and neuroimaging to reach the diagnosis of FES. ${ }^{16}$

Finally, according to Lindeque et al, FES can be diagnosed on the basis of respiratory parameters alone. ${ }^{48}$

However, all these diagnostic tools have not been validated in prospective studies and there is no clear evidence of their sensitivity and specificity; this, therefore, limits their practical usefulness. In our opinion, the Gurd's modified criteria should be preferred because of the inclusion of neuroimaging evaluation besides the clinical features.

Laboratory tests are nonspecific and lack sufficient sensitivity. For this reason, none of them is recommended for routine diagnostic management and, when included in the diagnostic criteria, they are considered only as minor criteria (Table 1). ${ }^{22,49}$ Cytological examination of the urine and sputum may show fat globules but their absence does not exclude FES..$^{22,49}$ Bronchoalveolar lavage may reveal fat droplets, which can be free or inside macrophages, but this finding is not specific because it has also been reported in patients with sepsis or under propofol infusion. ${ }^{50}$ Finally, cytology of pulmonary capillary blood, performed through a wedged pulmonary artery catheter, shows fat globules in patients with FES. ${ }^{51}$

Although FES diagnosis is based on clinical features, imaging studies can help and speed up the diagnosis.

When examining the lungs, different imaging modalities can be used: chest radiography, ventilation/perfusion imaging of the lungs, and spiral chest computed tomography (CT). However, as is the case for laboratory tests, all these instrumental tests lack specificity and in some cases, sensitivity, that is, some patients with FES can show a normal chest film or the findings detected can also be seen in patients with pulmonary hemorrhage or pulmonary edema..$^{35}$

When examining the brain, neuroimaging, brain CT and, above all, MRI have become undoubtedly indispensable, especially for CFE diagnosis, since there are no clear diagnostic criteria for CFE and the diagnosis is mainly based on medical history and clinical manifestations. As shown in Table 1, Lee et al proposed the modified Gurd's criteria that include MRI to define cerebral involvement more accurately. ${ }^{16}$ According to these criteria, the diagnosis of FES can be made only if patients show brain MRI patterns compatible with microembolic phenomena associated with the presence of at least one major and three minor features, or two major plus two minor features and in the absence of other discernible causes to explain the clinical and instrumental findings. According to Kuo et al, MRI of the brain is considered the gold standard to diagnose CFE. ${ }^{52}$ However, the different studies of the imaging of CFE are confusing, with different descriptions of timing, distribution, size, and reversibility of the brain lesions. ${ }^{19,53,54}$ This is probably due to the small number of CFE cases examined by MRI, its different timings, and the fact that CFE is a dynamic process with specific time windows for imaging patterns. In addition, MRI sequences, such as diffusion-weighted imaging (DWI) and susceptibilityweighted imaging (SWI), are more sensitive compared with the sequences performed in routine diagnostic management (fluid-attenuated inversion recovery and T2-weighted imaging [T2WI]) for detecting pathognomonic patterns of CFE (such as the starfield pattern) at an early stage or specific types of brain lesion (such as petechial hemorrhage of white matter). Thus, when there is clinical suspicion of CFE, performing DWI and SWI, especially at an early stage after the onset of neurological symptoms, is an important goal to achieve a more rapid diagnosis. ${ }^{52}$

At an acute stage, the dominant and most frequent pattern is represented by the starfield pattern (Figure 1), characterized by multiple, scattered, small, and hyperintense lesions on a dark background, localized in both the white and deep gray matter, such as the centrum semiovale, basal ganglia, and thalami, along particular boundary zones of major vascular territories. ${ }^{54,55}$ This is the most well-known pattern of CFE, even though it is a nonspecific feature as it is observed in all

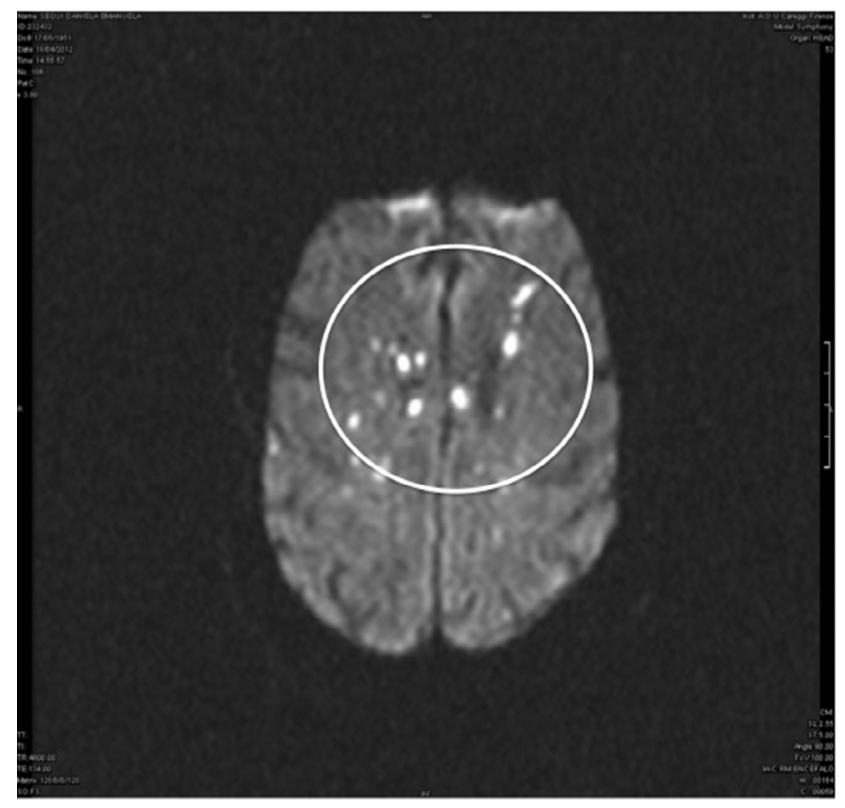

Figure I Brain MRI.

Note: Diffusion-weighted imaging: starfield pattern characterized by multiple, scattered, small, hyperintense lesions on a dark background, localized in white matter and deep gray matter bilaterally, indicated by white circle. 
kinds of embolic events. However, in CFE, these lesions are usually reversible. They are detected on DWI sequences as areas of restricted diffusion, whereas on T2WI, they can be iso- or hyperintense. This pattern is pathognomonic of the early stage of CFE, being much less frequent in the subacute and late stages. The pathogenesis of the starfield pattern is attributed to fat droplets $<20 \mu \mathrm{m}$, which are not blocked by the pulmonary filter, reaching the capillaries of the brain and resulting in ischemic injury. ${ }^{52}$ However, as mentioned earlier, this type of CFE lesions are usually reversible as fat vacuoles are in liquid form so they can deform, split into smaller globules, and recycle into the pulmonary circulation, with the consequent reperfusion of damaged tissues. ${ }^{56,57}$ This is probably the reason for the better clinical outcome of CFE compared with other embolic events. In the case of the absence of a pulmonary filter, such as in the presence of a patent foramen ovale, the onset of neurological manifestations is earlier, the brain lesions are larger, there are more territorial infarctions, and a worse clinical prognosis.

At the subacute stage, two different patterns can be observed. The first one is represented by confluent cytotoxic edema in white matter. On DWI sequences, it is characterized by confluent symmetric lesions with restricted diffusion, especially in periventricular and subcortical white matter bilaterally and also in the cerebellar peduncles, corpus callosum, and posterior internal capsule. On T2WI, the lesions are slightly hyperintense or in some cases, have no signal change. This pattern is a common and characteristic finding of CFE, although it is not always considered. Anamnestic features and laboratory tests are able to distinguish CFE from hypoglycemic encephalopathy, postanoxic encephalopathy, and toxic leukoencephalopathy in which a similar MRI pattern may also be present.

The other characteristic pattern of the subacute stage is represented by vasogenic edema lesions with possible enhancement. These lesions are usually small and patchshaped and are localized both in white and gray matter. They are hyperintense on T2WI, whereas they show increased diffusion on DWI sequences. In addition, they can show enhancement after contrast injection. ${ }^{52}$

SWI sequences make it possible to detect the presence of petechial hemorrhage, another characteristic pattern of CFE that is observed in all stages, because they can evaluate vascular structures, blood products, and changes in iron content. ${ }^{52,58-61}$ These tiny lesions, localized in the perivascular space at both the white and deep gray matter level in the cerebellum, brainstem, and corpus callosum, need to be distinguished from the petechial hemorrhage lesions present in diffuse axonal injury (DAI), another condition that, like CFE, can be observed after a traumatic event. However, on T2WI, CFE hemorrhagic lesions are usually more numerous and diffuse compared with those of DAI, which tends to produce larger and more linear hemorrhages. In addition, diffuse confluent diffusion restriction on DWI sequences is typical of CFE, whereas a few scattered foci are suggestive of DAI ${ }^{62}$

The pathogenesis of both cytotoxic/vasogenic edema and of the hemorrhagic lesions can be explained by the biochemical theory. Being toxic for the brain, the free fatty acids, produced in the body in a stressed state, lead from one side to cerebral cytotoxic edema onset and, from the other side, to the onset of vasogenic edema, by opening the blood-brain barrier. Thus, this process produces a discontinuity of the cerebral capillary endothelium with the spill of small fat vacuoles, red blood cells, and plasma fluid into the perivascular interstitial space. ${ }^{63}$ This process can explain not only the pathogenesis of the vasogenic edema onset but also the presence of hemorrhagic lesions.

Finally, at the late stage, most of the aforementioned lesions can result in brain atrophy. Sequelae of infarction, gliosis, and chronic demyelinization can also be detected in some cases as hyperintense dot-shaped lesions in T2WI and increased diffusion on DWI sequences. ${ }^{52}$

In general, MRI lesions reflect what can be observed during autopsy evaluation, in which the principal findings are characterized by multiple hemorrhagic petechiae, mainly at the white matter level, breakdown of the endothelium and the blood-brain barrier, vasogenic edema, and small infarcts. ${ }^{53,64}$

According to the literature, brain computed tomography is considered less sensitive and specific than MRI, and in fact, it may be normal or show nonspecific signs of diffuse edema. ${ }^{3,434,35}$ However, it may also show bizarre, scattered, hypodense round lesions with the specific density of fat, suggesting CFE (Figure 2). This is a very important point because, in some cases, MRI findings may be nonspecific, hampering the diagnosis of CFE, whereas density measurement of the round lesions on brain CT makes it possible to reach the correct diagnosis. ${ }^{21}$

Another characteristic brain CT feature suggesting CFE is the presence of the "hypodense artery sign" indicating the presence of a macroscopic embolus with the density of fat. This pattern is usually present in patients who develop CFE after cardiac surgery and is the consequence of intracranial vessel occlusions, which give rise to large territorial infarcts. ${ }^{65,66}$ It is mandatory to distinguish this brain CT pattern, pathognomonic of CFE, from the "hyperdense artery sign", which indicates instead the presence of an acute thrombus. ${ }^{66}$ 
Table 2 shows the characteristic brain MRI and CT patterns of CFE at the different timing after the event.

Transcranial Doppler ultrasound (TCD) can be used to detect microembolic signals (MES) in patients with CFE. MES are found in $20 \%-100 \%$ of CFE patients, and they are characterized by low counts of high-intensity transient signal $(<10)$. However, some patients may show a high count. ${ }^{67} \mathrm{MES}$ are detected from 36 hours after the trauma and can persist up to 10 days after the event. ${ }^{68}$ Another TCD parameter to take into account for CFE diagnosis is the occurrence of a very high mean velocity value (about $160 \mathrm{~cm} / \mathrm{sec}$ ) associated with a markedly dilated arterial diameter. These findings are highly suggestive of marked hyperemia associated with the biochemical pathogenesis of CFE. ${ }^{69}$

Electroencephalogram is another instrumental test that may be useful when patients show a sudden onset of neurological signs and symptoms. As mentioned earlier, seizures are a frequent neurological manifestation after CFE. Patients

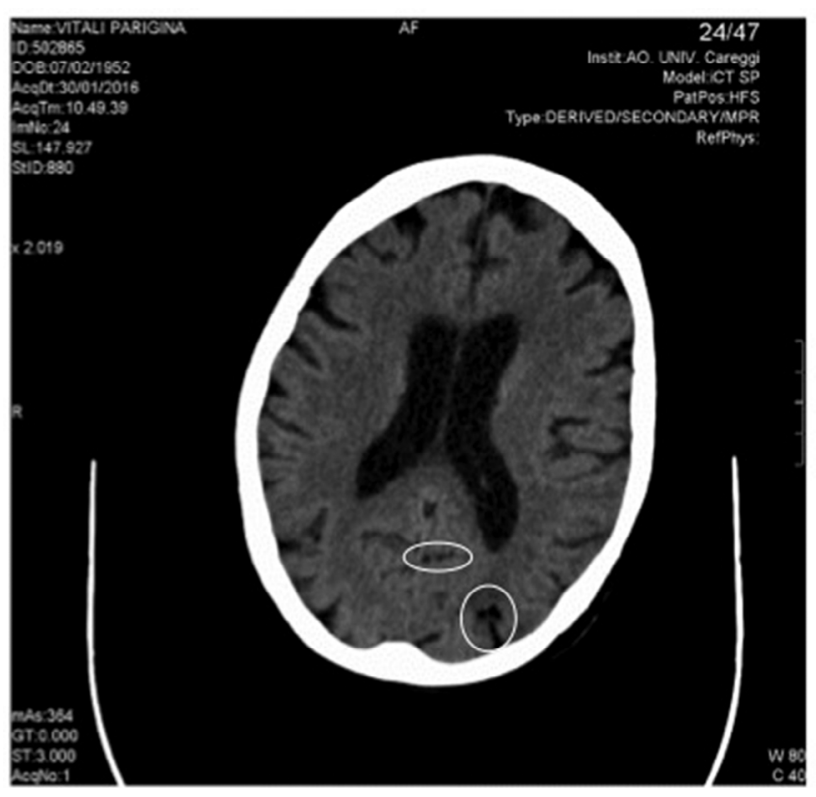

Figure 2 Brain computed tomography.

Note: Small left occipital fat hypodensity, indicated by white circles. may show focal or generalized tonic-clonic seizures but sometimes they may suffer nonconvulsive status epilepticus (NCSE), with only the presence of an alteration in consciousness (Figure 3). Detecting the eventual presence of an NCSE is a very important goal because often the extent of the neurological symptoms is mainly due to the presence of this ictal activity and is not correlated with the presence of cerebral lesions. Thus, resolution of the NCSE can lead to a sudden improvement in the neurological manifestations. ${ }^{23}$

\section{CFE prevention and treatment}

As mentioned previously, CFE is often self-limiting but it may also be fatal, and thus, prevention and appropriate diagnostictherapeutic management is important to reduce both mortality and severe disability. Prevention of CFE/FES consists of controlling or eliminating risk factors by early (within the first 24 hours) immobilization, stabilization, and external or internal fixation in the case of long-bone fractures. ${ }^{5,13,33}$ At the same time, external fixation or fixation with plates and screws results in FE less frequently than nailing the medullary cavity. Moreover, venting the medullary canal during nailing reduces the number of fat emboli. Finally, small diameter nails and unreamed nailing may be useful in prevention of CFE/FES. ${ }^{10,13}$ In addition, the use of corticosteroids (CCS) is thought to be beneficial for preventing FE, having anti-inflammatory effects and beneficial effects on the stabilization of membranes and the reduction of capillary permeability. ${ }^{47,70}$ However, published findings concerning the use of CCS are conflicting. Thus, some authors have reported that even though CCS can reduce the incidence of FES, the mortality rate is not affected, whereas other authors have reported a beneficial effect of the use of intravenous dexamethasone, especially at an early stage after the onset of symptoms, not only for FE prevention but for treatment too. ${ }^{71,72}$ Therefore, CCS therapy with the use of dexamethasone or methylprednisolone is, however, recommended, above all because, to date, there are no specific treatment guidelines either for FES or for CFE, and symptomatic and supportive therapy remains the main treatment

Table 2 Characteristic brain MRI and CT patterns of CFE at the different timing after the event

\begin{tabular}{|c|c|c|c|}
\hline \multirow[t]{2}{*}{ MRI } & Early stage & Subacute stage & Late stage \\
\hline & $\begin{array}{l}\text { - DWI: Starfield pattern } \\
\text { - SWI: Petechial hemorrhage }\end{array}$ & $\begin{array}{l}\text { - DWI: Cytotoxic edema } \\
\text { - T2WI: Vasogenic edema } \\
\text { - TIWI with enhancement: vasogenic edema } \\
\text { - SWI: petechial hemorrhage }\end{array}$ & $\begin{array}{l}\text { - T2Wl: - Gliosis } \\
\text { - Sequelae of infarction } \\
\text { - Chronic demyelinization } \\
\text { - Brain atrophy }\end{array}$ \\
\hline Brain CT & \multicolumn{3}{|c|}{$\begin{array}{l}\text { - Hypodense round lesions with specific density of fat } \\
\text { - Diffuse edema/specific signs }\end{array}$} \\
\hline
\end{tabular}

Abbreviations: DWI, diffusion-weighted imaging; SWI, susceptibility-weighted imaging; TIWI, TI-weighted imaging; T2WI, T2-weighted imaging; CT, computed tomography; CFE, Cerebral fat embolism. 


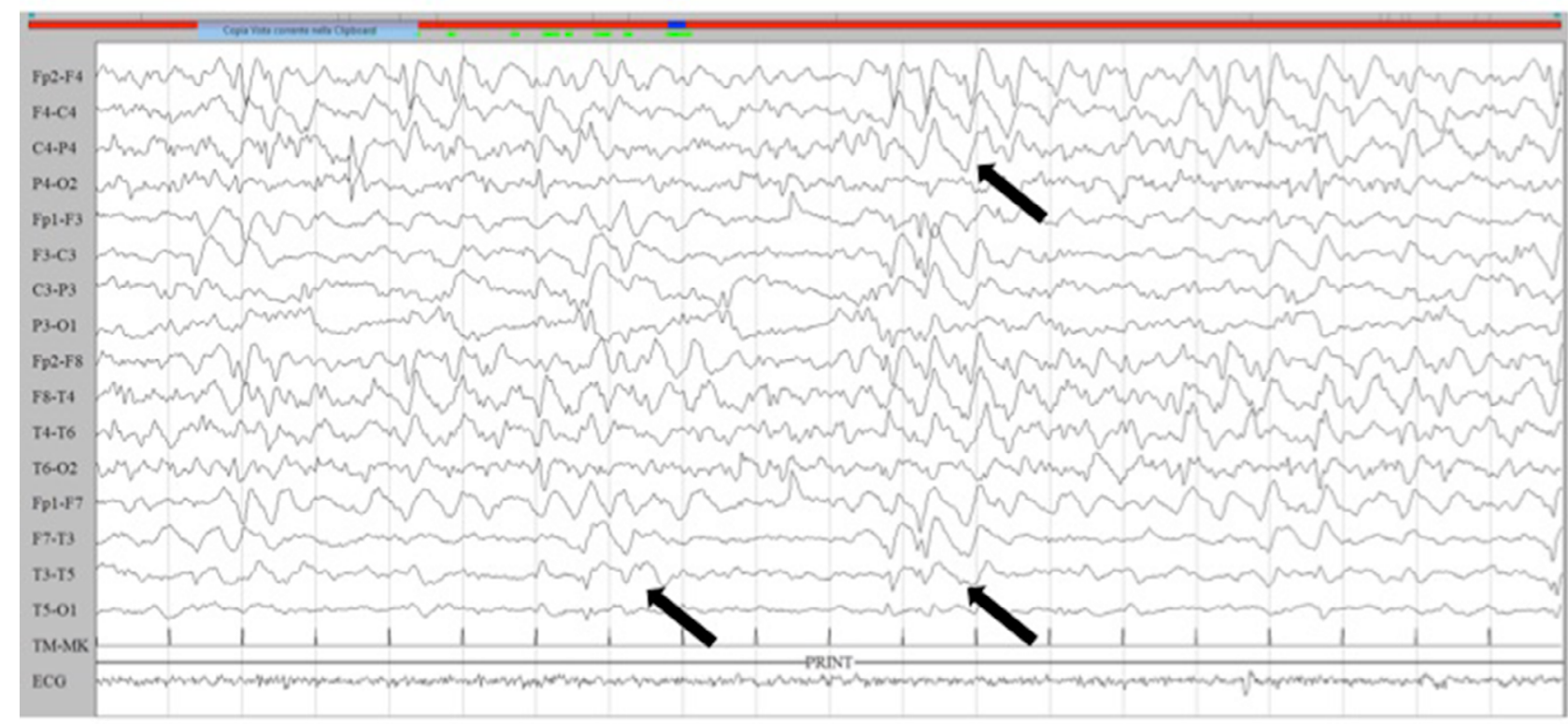

Figure 3 Electroencephalogram.

Notes: Lateralized periodic discharges with background attenuation on the left hemisphere, and sharp and slow wave activity on the right hemisphere, as indicated by black arrows.

nowadays. ${ }^{5,13,40}$ For example, heparin has been proposed for CFE/FES treatment, having a stimulatory effect on lipase activity and clearance of lipid from the circulation. Anyway, an increase in free fatty acids in the circulation can empower the underlying proinflammatory process. Anticoagulant drugs have also been proposed for FE treatment but their use is potentially dangerous in patients with trauma or preexisting hematologic abnormalities. ${ }^{35}$ Other treatments include the use of $20 \%$ sodium dehydrocholate or low molecular dextran, the use of albumin that binds with the fatty acids restoring blood volumes, the use of 5\% alcohol glucose solution that can inhibit the formation of fat droplets, or the use of lipid-soluble drugs; in fact, fat emboli can be dissolved by soluble saponin, which can be synthesized from $5 \%$ sodium bicarbonate and fat. ${ }^{40}$ However, the data supporting the use of these treatments are conflicting, since other authors have reported that their use is ineffective. In addition, adequate hemodynamic support, treatment of hypoxemia, prevention of the onset of a septic state, and prompt identification of neurological manifestations are obviously an important therapeutic goal. ${ }^{5,13,34}$ With regard to CFE treatment in particular, a dehydrating agent and head cooling therapy can be used to protect brain function. To decrease brain edema, lower metabolism in the brain cells, brain tissue oxygen improvement, cerebral tonic, and sedative drugs can be used ${ }^{40}$ In particular, sedative drugs can be used to keep intracranial pressure values under control or to limit the sympathetic response to the injury. ${ }^{35}$ In addition, when seizures are present, adequate anti-epileptic treatment should be started. Finally, the efficacy of early hyperbaric oxygen therapy has been confirmed. It increases blood oxygen pressure and oxygen content, and at the same time, the diffusion of oxygen in the capillaries of the brain tissue, with the result of improving microcirculation. It can also stimulate capillary growth to promote the development of collateral circulation, restoring the function of brain cells in the penumbral area and improving the function of the reticular activating system in the brainstem, resulting in an improvement in the state of consciousness. ${ }^{40}$

\section{CFE prognosis}

CFE is usually a self-limiting condition with a favorable prognosis characterized by complete recovery within a few weeks/months or years..$^{34,35,73}$ However, it may also be characterized by an ominous prognosis with a mortality rate of up to $10 \%$, above all in patients with increased age and multiple preexisting medical diseases. ${ }^{5,8,13}$ In other cases, patients may show residual neurological deficits, ranging from subtle personality changes, memory loss or cognitive dysfunction to focal deficits. ${ }^{74}$

At an early stage after the onset of neurological manifestations, detecting the presence of an NCSE is a very important goal, because in some cases, the extent of neurological signs and symptoms is correlated with the presence of status epilepticus (SE), rather than the extent of brain lesion 
damage. ${ }^{23}$ The presence of an SE, especially when presenting as an NCSE, could represent a confounding factor, above all for the purpose of giving the correct neurological prognosis. In fact, in some cases, early detection of the presence of an NCSE avoids giving an overly pessimistic neurological prognosis. However, some cases of super-refractory NCSE with an ominous prognosis have also been reported. ${ }^{75}$

Finally, neuroimaging is useful not only for diagnostic management but also for prognostic purposes. The extent of brain atrophy is usually related to the clinical prognosis, but the distribution and size of lesions in T2WI sequences can also be correlated with the final clinical prognosis. ${ }^{52}$ Finally, according to Takahashi et al, a good outcome is more likely to be associated with the disappearance of MRI lesions after 2 months. ${ }^{56}$

\section{Conclusion}

CFE is a very uncommon but potentially fatal condition that poses a diagnostic challenge, above all when secondary to uncommon nontraumatic causes of FE. In addition, it may be difficult to differentiate this condition from other neurological disease when presenting in an isolated form and not associated with pulmonary and dermatological manifestations. This is mainly because the neurological signs and symptoms are variable and nonspecific and do not satisfy the main diagnostic criteria proposed in the literature. However, neuroimaging, especially MRI with the use of DWI and SWI sequences, but in some cases, brain CT too, can hasten the diagnosis, avoiding other unnecessary investigations and treatment. CFE treatment is mainly supportive. To date, prophylactic strategies are considered an important tool to reduce the development of FE and consequently the incidence of CFE.

\section{Disclosure}

The authors report no conflicts of interest in this work.

\section{References}

1. Sevitt S. The significance and pathology of fat embolism. Ann Clin Res. 1977;9(3):173-180.

2. Aman J, van Koppenhagen L, Snoek AM, van der Hoeven JG, van der Lely AJ. Cerebral fat embolism after bone fractures. Lancet. 2015;386(10001):e16.

3. Mijalski C, Lovett A, Mahajan R, Sundararajan S, Silverman S, Feske S. Cerebral fat embolism: a case of rapid-onset coma. Stroke. 2015;46(12):251-253.

4. Jacobson DM, Terrence CF, Reinmuth OM. The neurologic manifestations of fat embolism. Neurology. 1986;36(6):847-851.

5. Kellogg RG, Fontes RB, Lopes DK. Massive cerebral involvement in fat embolism syndrome and intracranial pressure management. J Neurosurg. 2013;119(5):1263-1270.

6. Eguia P, Medina A, Garcia-Monco JC, Martin V, Monton FI. The value of diffusion-weighted MRI in the diagnosis of cerebral fat embolism. J Neuroimaging. 2007;17(1):78-80.
7. Han YT, Tang J, Gao ZQ, Hu HT. Clinical features and neuroimaging findings in patients with cerebral fat embolism. Chin Med J. 2016;129(7):874-876.

8. Kosova E, Bergmark B, Piazza G, Fatembolismsyndrome PG. Fat embolism syndrome. Circulation. 2015;131(3):317-320.

9. Gurd AR. Fat embolism: an aid to diagnosis. J Bone Joint Surg Br. 1970;52(4):732-737.

10. Shaikh N, Parchani A, Bhat V, Kattren MA. Fat embolism syndrome: clinical and imaging considerations: case report and review of literature. Indian J Crit Care Med. 2008;12(1):32-36.

11. Bulger EM, Smith DG, Maier RV, Jurkovich GJ. Fat embolism syndrome. A 10-year review. Arch Surg. 1997;132(4):439.

12. Fabian TC, Hoots AV, Stanford DS, Patterson CR, Mangiante EC. Fat embolism syndrome: prospective evaluation in 92 fracture patients. Crit Care Med. 1990;18(1):42-46.

13. Shaikh N. Emergency management of fat embolism syndrome. J Emerg Trauma Shock. 2009;2(1):29-33.

14. Georgopoulos D, Bouros D. Fat embolism syndrome: clinical examination is still the preferable diagnostic method. Chest. 2003;123(4):982-983.

15. Talbot M, Schemitsch EH. Fat embolism syndrome: history, definition, epidemiology. Injury. 2006;37(4):S3-S7.

16. Lee SC, Yoon JY, Nam CH, Kim TK, Jung KA, Lee DW. Cerebral fat embolism syndrome after simultaneous bilateral total knee arthroplasty: a case series. J Arthroplasty. 2012;27(3):409-414.

17. Lützen N, Niesen WD, Kalbhenn J, Urbach H. Teaching neuroimages: cerebral fat embolism after cemented hip replacement. Clin Neuroradiol. 2016;26(2):249-250.

18. Herway ST, Slotto J, Harlan E, Newhouse B. Cerebral fat embolism syndrome. Anesthesiology. 2016;124(5):1167.

19. Butteriss DJ, Mahad D, Soh C, Walls T, Weir D, Birchall D. Reversible cytotoxic cerebral edema in cerebral fat embolism. AJNR Am J Neuroradiol. 2006;27(3):620-623.

20. Fazekas IG. Fatal fat embolism following multiple rib fractures due to forced sexual intercourse. Magy Noorv Lapja. 1963;26:326-330.

21. Scarpino M, Lanzo G, Moretti M, Olivo G, Amantini A, Grippo A. Delayed cerebral fat embolism occurring after off-pump coronary artery bypass grafting. Cardiol J. 2018;25(1):155-157.

22. Akhtar S. Fat embolism. Anesthesiol Clin. 2009;27(3):533-550.

23. Scarpino M, Lanzo G, Cappelli F, et al. Cerebral fat embolism after videoassisted thoracic surgery. Ann Thorac Surg. 2016;102(5):e409-e411.

24. Ten Duis HJ. The fat embolism syndrome. Injury. 1997;28(2): 77-85.

25. Shapiro MP, Hayes JA. Fat embolism in sickle cell disease: report of a case with brief review of literature. Arch Intern Med. 1984;14:181-182.

26. Scheifer C, Lionnet F, Bachmeyer C, et al. Cerebral fat embolism in hemoglobin SC disease. Am J Med. 2017;130(5):e187-e189.

27. Shen $\mathrm{X}$, Li Q, Zhang H. Massive cerebral infarction following facial fat injection. Aesthetic Plast Surg. 2016;40(5):801-805.

28. Kammeyer R, Devnani R, Mehta R. Cerebral fat embolism syndrome mimicking thrombotic thrombocytopenic purpura in a patient with hemoglobin SC disease. Am J Hematol. 2016;91(5):539-542.

29. Whalen LD, Khot SP, Standage SW. High-dose rosuvastatin treatment for multifocal stroke in trauma-induced cerebral fat embolism syndrome: a case report. Pediatr Neurol. 2014;51(3):410-413.

30. Yilmaz A, Kurt S, Sarikaya B, Murat Firat M, Ocal S, Yeginsu A. Recurrent cerebral fat embolism due to pleural irrigation: fat density lesions on CT. a case report. Neuroradiol J. 2007;20(3):287-290.

31. Bugnitz CJ, Cripe LH, Lo WD, Flanigan KM. Recurrent fat embolic strokes in a patient with Duchenne muscular dystrophy with long bone fractures and a patent foramen ovale. Pediatr Neurol. 2016;63:76-79.

32. Dillerud E. Abdominoplasty combined with suction lipoplasty: a study of complications, revisions, and risk factors in 487 cases. Ann Plast Surg. 1990;25(5):333-343.

33. Robert JH, Hoffmeyer P, Broquet PE, Cerutti P, Vasey H. Fat embolism syndrome. Orthop Rev. 1993;22(5):567-571. 
34. Godoy DA, Di Napoli M, Rabinstein AA. Cerebral fat embolism: recognition, complications, and prognosis. Neurocrit Care. Epub 2017 Sep 20.

35. Uransilp N, Muengtaweepongsa S, Chanalithichai N, Tammachote N. Fat embolism syndrome: a case report and review literature. Case Rep Med. 2018;2018:1479850.

36. Glossing HR, Pellegrini VD. Fat embolism syndrome: a review of pathology and physiological basis of treatment. Clin Orthop Relat Res. 1982;165:68-82.

37. Baker PL, Pazell JA, Peltier LF. Free fatty acids, catecholamines, and arterial hypoxia in patients with fat embolism. J Trauma. 1971;11(12):1026-1030.

38. Nastanski F, Gordon WI, Lekawa ME. Posttraumatic paradoxical fat embolism to the brain: a case report. J Trauma. 2005;58(2):372-374.

39. George J, George R, Dixit R, Gupta RC, Gupta N. Fat embolism syndrome. Lung India. 2013;30(1):47-53.

40. Zhou Y, Yuan Y, Huang C, Hu L, Cheng X. Pathogenesis, diagnosis and treatment of cerebral fat embolism. Chin J Traumatol. 2015;18(2):120-123.

41. Powers KA, Talbot LA. Fat embolism syndrome after femur fracture with intramedullary nailing: case report. Am J Crit Care. 2011;20(3):4-6.

42. Gupta B, Kaur M, D’Souza N, et al. Cerebral fat embolism: a diagnostic challenge. Saudi J Anaesth. 2011;5(3):348-352.

43. Meena UK, Lamoria RK, Millan RK, Agarwal P, Singh M, Bansal MC. Cortical blindness along with motor aphasia: an unusual presentation of fat embolism syndrome. J Clin Orthop Trauma. 2016;7(Suppl 1): $17-21$

44. Wang $\mathrm{CH}$, Chang PY, Wu JC, et al. Hydrocephalus caused by fat embolism: a rare complication of atlanto-axial fixation for odontoid fractures. World Neurosurg. 2016;90:700.e7-e12.

45. Mittal MK, Burrus TM, Campeau NG, Eckel LJ, Rabinstein AA, Wijdicks EF. Pearls \& oysters: good recovery following cerebral fat embolization with paroxysmal hyperactivity syndrome. Neurology. 2013;81(14):107-109.

46. von Bergmann E. Ein fall todlicher fettenbolic [incidence of the deadly fat embolism]. Berl Klin Wochenscher. 1873;10:385. German.

47. Schonfeld SA, Ploysongsang Y, Dilisio R, et al. Fat embolism prophylaxis with corticosteroids. a prospective study in high-risk patients. Ann Intern Med. 1983;99(4):438-443.

48. Lindeque BG, Schoeman HS, Dommissen GF, Boeyens MC, Vlow AL. Fat embolism syndrome: a double blind therapeutic study. J Bone Joint Surg Br. 1987;69:128-131.

49. Chan KM, Tham KT, Chiu HS, Chow YN, Leung PC. Post-traumatic fat embolism: its clinical and subclinical presentations. J Trauma. 1984;24(1):45-49.

50. Roger N, Xaubet A, Agustí C, et al. Role of bronchoalveolar lavage in the diagnosis of fat embolism syndrome. Eur Respir J. 1995;8(8): 1275-1280.

51. van den Brande FG, Hellemans S, de Schepper A, et al. Post-traumatic severe fat embolism syndrome with uncommon CT findings. Anaesth Intensive Care. 2006;34(1):102-106.

52. Kuo KH, Pan YJ, Lai YJ, Cheung WK, Chang FC, Jarosz J. Dynamic MR imaging patterns of cerebral fat embolism: a systematic review with illustrative cases. AJNR Am J Neuroradiol. 2014;35(6):1052-1057.

53. Simon AD, Ulmer JL, Strottmann JM. Contrast-enhanced MR imaging of cerebral fat embolism: case report and review of the literature. $A J N R$ Am J Neuroradiol. 2003;24(1):97-101.

54. Parizel PM, Demey HE, Veeckmans G, et al. Early diagnosis of cerebral fat embolism syndrome by diffusion-weighted MRI (starfield pattern). Stroke. 2001;32(12):2942-2944.
55. Guillevin R, Vallée JN, Demeret S, et al. Cerebral fat embolism: usefulness of magnetic resonance spectroscopy. Ann Neurol. 2005;57(3):434-439.

56. Takahashi M, Suzuki R, Osakabe Y, et al. Magnetic resonance imaging findings in cerebral fat embolism: correlation with clinical manifestations. J Trauma. 1999;46(2):324-327.

57. Brown WR, Moody DM, Challa VR. Cerebral fat embolism from cardiopulmonary bypass. J Neuropathol Exp Neurol. 1999;58(2):109-119.

58. Suh SI, Seol HY, Seo WK, Koh SB. Cerebral fat embolism: susceptibility-weighted magnetic resonance imaging. Arch Neurol. 2009;66(9):1170.

59. Zaitsu Y, Terae S, Kudo K, et al. Susceptibility-weighted imaging of cerebral fat embolism. J Comput Assist Tomogr. 2010;34(1):107-112.

60. Malgapo KKL, Osman C, Prevett M. Cerebral fat embolism: the value of susceptibility-weighted imaging. Pract Neurol. 2018;18(4):336-338.

61. Burns JD, Noujaim D, Scott BJ. Susceptibility-weighted imaging diagnosis of cerebral fat embolism. Neurohospitalist. 2017;7(3):147.

62. Rutman AM, Rapp EJ, Hippe DS, Vu B, Mossa-Basha M. T2*-weighted and diffusion magnetic resonance imaging differentiation of cerebral fat embolism from diffuse axonal injury. $J$ Comput Assist Tomogr. 2017;41(6):877-883.

63. Kim HJ, Lee CH, Lee SH, et al. Early development of vasogenic edema in experimental cerebral fat embolism in cats: correlation with MRI and electron microscopic findings. Invest Radiol. 2001;36(8):460-469.

64. Kamenar E, Burger PC. Cerebral fat embolism: a neuropathological study of a microembolic state. Stroke. 1980;11(5):477-484.

65. Lee TC, Bartlett ES, Fox AJ, Symons SP. The hypodense artery sign. AJNR Am J Neuroradiol. 2005;26(8):2027-2029.

66. Avila JD. Hypodense artery sign in cerebral fat embolism. Pract Neurol. 2017;17(4):304-305.

67. Silbert BS, Evered LA, Scott DA, Rahardja S, Gerraty RP, Choong PF. Review of transcranial Doppler ultrasound to detect microemboli during orthopedic surgery. AJNR Am J Neuroradiol. 2014;35(10): 1858-1863.

68. Forteza AM, Koch S, Campo-Bustillo I, et al. Transcranial Doppler detection of cerebral fat emboli and relation to paradoxical embolism: a pilot study. Circulation. 2011;123(18):1947-1952.

69. Saleh M, Juan E. Cerebral fat emboli syndrome: do not miss the transcranial Doppler findings. BMJ Case Rep. 2015;2015pii:bcr2015210445.

70. Cavallazzi R, Cavallazzi AC. The effect of corticosteroids on the prevention of fat embolism syndrome after long bone fracture of the lower limbs: a systematic review and meta-analysis. J Bras Pneumol. 2008;34(1):34-41.

71. Bederman SS, Bhandari M, Mckee MD, Schemitsch EH. Do corticosteroids reduce the risk of fat embolism syndrome in patients with long-bone fractures? A meta-analysis. Can J Surg. 2009;52(5):386-393.

72. Xu XL, Xu P, Zheng RQ, Lin H, Chen QH. A case of cerebral fat embolism. Chin Med J. 2016;129(14):1761-1762.

73. Lin KY, Wang KC, Chen YL, Lin PY, Lin KH. Favorable outcome of cerebral fat embolism syndrome with a Glasgow coma scale of 3: a case report and review of the literature. Indian J Surg. 2015;77(Suppl 1):46-48.

74. Al-Shaer DS, Ayoub O, Ahamed NA, Al-Hibshi AM, Baeesa SS. Cerebral fat embolism syndrome following total knee replacement causing a devastating neurocognitive sequelae. Neurosciences. 2016;21(3):271-274.

75. Fernandez-Torre JL, Burgueño P, Ballesteros MA, Hernández-Hernández MA, Villagr-Terán N, de Lucas EM. Super-refractory nonconvulsive status epilepticus secondary to fat embolism: a clinical, electrophysiological, and pathological study. Epilepsy Behav. 2015;49:184-188. 


\section{Publish your work in this journal}

The International Journal of General Medicine is an international, peer-reviewed open-access journal that focuses on general and internal medicine, pathogenesis, epidemiology, diagnosis, monitoring and treatment protocols. The journal is characterized by the rapid reporting of reviews, original research and clinical studies across all disease areas.
The manuscript management system is completely online and includes a very quick and fair peer-review system, which is all easy to use. Visit http://www.dovepress.com/testimonials.php to read real quotes from published authors.

Submit your manuscript here: https://www.dovepress.com/international-journal-of-general-medicine-journal 